RESENHA

\author{
CARO, Sueli Maria Pessagno; GUZZO, \\ Raquel Souza Lobo. Educação social \\ e psicologia. Campinas: Editora \\ Alínea, 2004. 108p.*
}

\title{
EDUCAÇÃO SOCIAL: UMA PROPOSTA VOLTADA À CIDADANIA
}

O livro retrata objetivamente os diferentes aspectos da educação social, abordando tópicos referentes às características presentes em tal área do conhecimento, enfatizando os principais aspectos necessários à boa ou satisfatória atuação dos educadores sociais e como se encontra esse campo do saber na realidade brasileira.

Sueli Maria Pessagno Caro é psicóloga, especialista em psicologia social e educação social pelo Centro Universitário Salesiano de São Paulo (UNISAL), mestre em psicologia escolar e doutora em psicologia pela Pontifícia Universidade Católica de Campinas (PUC-Campinas), professora do Programa de Mestrado em Educação do UNISAL de Americana, São Paulo. Raquel Souza Lobo Guzzo é psicóloga, doutora em psicologia escolar pela Universidade de São Paulo (USP), pós-doutora em prevenção pela Universidade de Rochester, Nova Iorque, Estados Unidos, professora do curso de psicologia da PUC-Campinas e coordenadora do Grupo de Pesquisa Avaliação e Intervenção Psicossocial: Prevenção, Comunidade e Libertação.

O prefácio é assinado pelo professor doutor Edson Donizetti Castilho, pró-reitor de pesquisa e pós-graduação do UNISAL no período de publicação da referida obra, que destaca quanto o Brasil necessita desenvolver, investir e pesquisar as áreas relativas à educação, particularmente no que tange à educação social, enfatizando que o sistema brasileiro precisa seguir os exemplos apresentados por vários países europeus, tais como Espanha e Itália, estabelecendo uma consolidada valorização, estruturação e formação dos educadores sociais, considerando que eles podem ser capazes de promover maior conscientização da população em relação à cidadania e a seus direitos como cidadãos. * Este texto foi revisado pela professora Ana Valéria Sampaio de Almeida Reis, mestre
em linguística aplicada pela Universidade de Taubaté. 
O livro conta com três capítulos, apresentando também introdução e conclusão.

As autoras destacam inicialmente a importância da educação como ferramenta de combate à exclusão social, desenvolvendo nos sujeitos marginalizados maior senso de cidadania e conscientização dos próprios direitos, revelando que a interdisciplinaridade possibilitaria uma maior abrangência e qualidade na atuação dos profissionais educadores. No mesmo espaço é enfatizada a ausência de maiores investimentos nos setores da educação social, como na formação, capacitação e atuação dos educadores sociais. Tal situação necessita mudar, uma vez que educadores são capazes de modificar a realidade e proporcionar a transformação social dos excluídos.

No primeiro capítulo, o livro aponta para diversos posicionamentos distintos em torno da educação formal, informal e não formal. O capítulo comenta a adaptação que surge com a escola formal, ao mesmo tempo em que relata de maneira sucinta o caminho da educação através dos tempos, a evolução das propostas e métodos de ensino e também a aceitação desses artifícios pelos educandos. Percebe-se no capítulo a seriedade da educação escolar e suas dimensões em um processo educativo que se constrói ao longo da vida e a pessoa como ser que sente, age, pensa e que precisa ser respeitada. Por fim, ocorre a ênfase à pedagogia libertadora, que vem ao encontro das necessidades presentes, demonstradas na sociedade ao longo dos anos e em um contexto de luta contra a desumanização.

No segundo capítulo, aborda-se o fato de o educador social desempenhar uma gama de ações, abrangendo desde atitudes pedagógicas e intervenções sociais até orientações e aconselhamentos, comprometendo-se com os setores sociais mais desfavorecidos, o que requer uma especial sensibilidade social. O profissional necessita conhecer o desenvolvimento humano, ter noção da situação sociopolítica do país, estar atento aos aspectos jurídicos e às políticas públicas e ter uma metodologia de trabalho coerente com o objetivo educacional. Assim, o aspecto profissional depende de sua integridade pessoal, sua capacidade de compreender e aceitar o outro sem julgamentos ou preconceitos e ter como metas a promoção do desenvolvimento e a orientação da comunidade, tornando-se capaz de intervir em diversos contextos e abranger de crianças a idosos, contando com um extenso campo de atuação.

Nesse mesmo capítulo também é retratada a participação da ideologia de Dom Bosco na educação social, pois, além de seu reconhecido sistema preventivo no âmbito da educação e a maneira de agir, ele demonstrou ser um grande conhecedor do comportamento humano, intervindo com jovens excluídos, visando a que eles fossem bons cristãos e cidadãos honestos.

Por fim, são enfatizados os constructos fundamentais na personalidade do educador social: a autoestima e a empatia, requisitos básicos para o afeto, o acolhimento, a familiaridade, o compromisso, o bom relacionamento e a responsabilidade, e a resiliência como suporte para a sustentação e o enfrentamento de situações conflituosas e complexas.

O capítulo três retrata a visão da área e do profissional da educação social no contexto brasileiro, enfatizando a necessidade de valorização para tal campo do conhecimento, salientando-se que não há consideração quanto à formação, atuação e papel do educador social em tal realidade. É destacado que ocorre uma divergência 
dos profissionais atuantes quanto à própria formação profissional e interesses e motivações para trabalhar nessa área. O capítulo termina enfatizando que o educador social deve estar ciente de sua responsabilidade na intervenção social e de seu poder de auxílio na comunidade.

As autoras finalizam ressaltando que os educadores sociais sentem satisfação e interesse pelo exercício dessa função, todavia a falta de identidade profissional e formação adequada dificultam a atuação, além de também necessitarem de constante atualização e acompanhamento em suas atividades, para que se concretizem adequadamente como ferramenta de transformação social e instrumentos de desenvolvimento sociocomunitário.

Salienta-se nessa obra o seu caráter didático, por proporcionar uma visão abrangente da educação social e do profissional que atua inserido nesse contexto de intervenção. Apresentado numa linguagem de fácil entendimento, o livro também possibilita uma análise crítica acerca da realidade dessa área e oferece reflexões sobre esse campo profissional. Enfim, as informações são apresentadas e definidas de maneira bastante clara e acessível, possibilitando a compreensão fidedigna do conteúdo proposto pelas autoras.

Percebe-se que esse livro pode ser visto como uma forte contribuição ao educador quanto ao entendimento de sua identidade e atuação, como também pode ser aproveitado por pesquisadores da área, uma vez que tal obra destaca fatores relevantes à prática e investigação desse campo do saber. Por fim, a obra mostra-se útil para professores e alunos no contexto universitário, por possibilitar uma visão introdutória no campo da educação social.

\section{SOBRE OS AUTORES}

Thiago Ribeiro Borges é graduado em psicologia pelo Centro Universitário Salesiano de São Paulo (UNISAL). Orientador acadêmico no Centro Universitário Internacional (UNINTER).

E-mail: thiago_rb2@yahoo.com.br

Flávio Aurélio de Souza Prado é graduado em psicologia pelo Centro Universitário Salesiano de São Paulo (UNISAL). Atua como psicólogo clínico. E-mail: flavio.aurelio.guara@hotmail.com

Pedro Ricardo Guimarães Veras é graduado em psicologia pelo Centro Universitário Salesiano de São Paulo (UNISAL). Atua como psicólogo clínico. E-mail: verasimovel@terra.com.br

Anelise de Barros Leite Nogueira é doutora em psicologia escolar e do desenvolvimento humano pela Universidade de São Paulo (USP). Professora no Centro Universitário Salesiano de São Paulo (UNISAL). E-mail: anelisebln@1o.unisal.br 